\title{
The Tunisian School Time allocated to the Matter of Sport and Physical Education
}

\author{
Habib Maaloul ${ }^{1}$, Nasr Chalghaf ${ }^{2}$, Abdelaziz Hentati ${ }^{1}$, Jaouhar Hamani ${ }^{1}$, \\ Fairouz Azaiez ${ }^{1,2}$ \\ 1-Higher institute of Sport and the Physical Education of Sfax (Tunisia). \\ 2-Studies Group of Development and Social Environment (Faculty of Letters and Social Sciences of Sfax).
}

\begin{abstract}
The Physical education and sports in schools contributes not only to the first good fitness and good health of students, but also helps young to achieve performance and better understand physical activity, with positive impact throughout life. In addition, physical education provides knowledge and transferable skills such as teamwork, fair play, respect grows, the body and social awareness, and provides general understanding of the "rules" that students can easily use in other school subjects or situations of life. Due to its many benefits, the promotion of physical activity has been increased at International level attention. Our research aims to probe the real situation of the matter within the school system from the time allocated to the matter at the law and above the level of everyday practice. 74 teachers of both sexes participated in this study. 48 male teachers with mean age $(21,5 \pm 8,8)$, and 26 female teachers (mean age: $17 \pm 10,9)$. We used two investigative tools. First an analysis of the laws governing the organization of teaching matters and school time to prep school and colleges (laws, decrees and ministerial notes). Second, a quantitative and qualitative analysis of schedules of a sample of teachers for two consecutive years (2007/2008 and 2008/2009). Our results chow a low use of the morning session in the teaching of EPS at the beginning and the weekend (Monday and Saturday) with a rate of (17\%) compared to the average. Moreover, the peak hours during the day are located in the middle of the morning sessions (9am to 1lam) and afternoon (15h to 17h).
\end{abstract}

Keywords: School time; Chronobiology; Sport and Physical Education (EPS)

\section{Introduction}

The concept of school time returns again to the center stage in the world, not only because of his close relationship with the notion of biological rhythms and the observations of chrono psychologists in the field of education, but also for multiple interference of school time with the quality of teaching, with the socioprofessional life parents, and working conditions of educational stakeholders: students, teachers, supervisors and administrators. In France, a new organization of school time was considered from the fall 2013 establishing a more balanced school week, organized in nine half-days ( 24 hours per week for 36 weeks) and a relief of the day teaching (5:00 30mn/day; 3 hours / half day) (1).

The German carrier of great concern within the family school system, children are left to themselves afternoon. An increase in juvenile delinquency was observed leading to a declining birth rate. These concerns are valid because the country injects 4 billion Euros to allow institutions to organize a full school day closer like the French system (2).

In Tunisia, the problem is much more difficult with a school system borrowed from the French model and uprooted from their socio-cultural environment. School time is considered by education specialists as "aberrant". After the Tunisian revolution of 14 January 2011, several attempts have been made to overcome the deficiencies in the school system, including that of the National Committee of school time organized by the Ministry of Education (3). It has completed its work on 07octobre 2012, but its recommendations are strong interesting to this dark days. Among the excess of the Tunisian educational system, we can easily identify: a too short school year, a week and a day too long overloaded. This imbalance has been fed over the last decade by the gradual injection of several school subjects (philosophy, physics, English and French ....), an ever-increasing volume of hours of general education subjects (32 to 36 hours / week against an average of $22 \mathrm{~h} /$ week worldwide). This has dramatically limited slots for cultural, artistic and sporting activities. Friday afternoon twelve o'clock originally booked to free cultural activities, is being diverted increasingly to teaching activities, catching or passing exams. In this context, it is appropriate to ask about the actual place of the EPS in the school system especially with the ministerial decision to reduce the number of hours of PE for students in secondary education in $3 \mathrm{~h} 2 \mathrm{~h} /$ week since 2002 (4), and the second decision in 2010 on the abolition of the baccalaureate exams sport national baccalaureate. 
Our research aims to probe the real situation of the matter within the school system from the time allocated to the material at the law and above the level of everyday practice. We also hope to compare the political discourse "Novembers" regime advocating a thriving physical education and sports, national and international (adoption by the UN in 2003 draft Zine El Abidine Ben Ali, the International Year of physical education and sports) (5) with the reality of the discipline in the preparatory and secondary schools through two indices: Quantity and Quality of school time allotted to the material in the Tunisian school context. Moreover, "the improvement of the student's concentration is possible through sport and respiratory muscle exercises and activities ..." (6).

The question is whether the school time to physical education and sports in Tunisia is sufficient quantitative point of view to satisfy the biological, intellectual and socio-emotional child in school and what matching slots allotted to the physical education and sports and alertness required in connection with the results of research conducted in the field of chronobiology and chrono psychology?

\section{1) The School Time:}

In these times of turmoil and reform in Tunisia, it's the education system that is in question. One of the priorities of the revolution is to reorganize school life so as a lever to improve the quality of education and to address the causes of school failure. The majority of education specialists believe that our students do not work hard enough and they have lots of holidays and vacations. Others believe that our children bend under the weight of schoolbags and endless hours of classes (7). The comparison with neighboring geographical area (Europe) allows to get more accurate picture of reality:

- The annual school calendar is about 165 day/year. Although this average is greater than that of France (140 days/year) (8), it remains well below the world average, which is about (180 days/year). (9).

- The weekly rate considered the heaviest: primary, it varies between 20 and $25 \mathrm{~h} /$ week. In college, it is limited to 32 hours / week, but in high school, it is higher (32 to 36 hours / week) up to 39h (3rd grade science experiments). (9) It is noted that the average weekly the European Union is 21 hours / week very close to the global average of $22 \mathrm{~h} /$ week.

- The daily rate in primary schools is 5 hours / day spread over 5.5 days. In middle school and high school, the rate is 7 to 8 hours / day.

- From a qualitative point of view, the time allocated to each subject is of great importance: the increasing importance attributed to language (58\% against $30 \%$ in Tunisia in the European Union). For mother tongue our students receive $30 \%$ and the rest in foreign languages. By cons, $13.5 \%$ of the time allotted to math against $20 \%$ in the EU, the sciences have $7.5 \%$ against $20 \%$ in the EU and artistic activities cover $5 \%$ of the time against 15 $\%$ in the EU (10). No information in the literature, we found only refers to the rate of physical education and sports activity within the Tunisian and European school system.

\section{2) The Chronobiology:}

Chronobiology is the study of biological rhythms and their alteration. It is used in the sense of its impact on physical and mental performance.The capacity of the individual depend indeed proper synchronization of these rhythms, the synchronization amputated many ways the quality of life and performance of the individual (11).

Many studies in chrono school psychology, show that the intellectual activity of students fluctuates during the day and also during the week (12);(13). Daily changes are often related to biological rhythms of the child while the weekly changes resulting from the influence of the schedule and school schedules.

\section{a) Daily variation of the intellectual activity of the child:}

The studies of (Testu 1994) and those of Europeans in general about the evolution of intellectual performance in children, show a similar classical profile. This profile is characterized by a decrease in vigilance from waking up to 8.30 - 9am (impact of sleep inertia on mental performance), an increase in performance over the school morning, followed by a fall after lunch (effect post - prandial), and then again an increase in vigilance during the after - noon. These daily fluctuations in alertness and mental performance are manifested in quantitative and qualitative terms.

\section{b) Weekly variation of the intellectual activity of the child:}

In the traditional system, $4 \mathrm{~h}$ and a half per week or five days, students perform better on Thursday and Friday and the worst on Monday and to a lesser degree on Saturday morning (15).

\section{c) Chronobiology physical performance of the child:}

It seems that most of the factors of physical and athletic performance (strength and muscle power, psychomotor performance and cardiovascular fitness) also fluctuate during the day. These variations are closely related to endocrine secretions and body temperature: Muscle strength peak between 17 and 19h. (16);(17), 
psychomotor performance (motor skills, movement coordination and response to stimuli) are closely related to the level of vigilance and follow the same pattern as intellectual movements for maximum endurance exercise over 40-50 minutes duration, it seems that the most favorable time slot is morning (15).

\section{Methods}

Our sample consists of a group of teachers from an entire inspection constituency without removal or selection. This is a convenience sample, which includes 74 teachers of both sexes participated in this study. The male is represented by 48 teachers with mean age $(21,5 \pm 8,8)$, and 26 female teachers(mean age: $17 \pm 10,9)$.

Table 1: The Sample's Characteristics

\begin{tabular}{|l|c|c|c|c|c|}
\hline \multirow{2}{*}{ Sexe } & \multicolumn{4}{|c|}{ General seniority } & \multirow{2}{*}{ Total } \\
\cline { 2 - 5 } & Moy $\pm \mathrm{ET}$ & {$[\mathrm{Min} ; \mathrm{Max}]$} & $<20$ years & $>$ 20years & \\
\hline Male & $8,8 \pm 21,5$ & {$[36 ; 5]$} & 20 & 28 & 48 \\
\hline Female & $10,9 \pm 17$ & {$[35 ; 3]$} & 17 & 9 & 26 \\
\hline Total & $\mathbf{9 , 7} \pm \mathbf{1 9 , 9}$ & {$[36 ; 3]$} & 37 & 37 & $\mathbf{7 4}$ \\
\hline
\end{tabular}

We used two investigative tools:

1 - Analysis of the laws governing the organization of teaching materials and school time to prep school and colleges (laws, decrees and ministerial notes)

2 - A quantitative and qualitative analysis of schedules of a sample of teachers for two consecutive years (2007/2008 and 2008/2009).

\section{Results}

1- Quantitative analysis of school time through the sample:

Basic Education (College School):

The physical education and sports is among 15 subjects of basic education. In terms of legislation in force, it has 3 hours a week on a total of 32 hours for all levels, which is (9.42\%), about 1/10 times the volume of students.

In reality, based on the results of our sample, it appears that the classes receiving only $3 \mathrm{~h}$ of physical education and sports about half (52.61\%), while the second half is not in accordance with the texts in defined in terms of excess or deficit. The average time given to all classes of 2 hours, 43 minutes with coverage reaching only $91.04 \%$, but the disparity between classes is obvious. It is between 1 to 4 hours per week of physical education and sports, which is a huge difference between the beneficiaries of the material. We conducted a rational redistribution of collective teaching of the establishments in question on the basis of 3 hours per week for all classes and we brought the rate of $100 \%$ coverage with an excess of two teachers and one part-time.

Basic Education (College School):

The legislative framework governing secondary institutions, the physical education and sports 12.2 among school matters (averaged over all levels and all sectors). It has a mandatory 2 hours and 1 hour optional out weekly through $34.28 \mathrm{~h}$, which represents only $5.83 \%$ of the hourly volume of students in secondary education (decisive phase in preparation for the physical education and sports baccalaureate) and a very regression significant compared to the preparatory stage.

In reality, based on the results of our sample, the average number of hours assigned to students was 2 hours, 13 minutes, representing a coverage rate higher than the standard (111.48\%). The disparity between the classes was evident: it is between 1 to 3 hours of physical education and sports per week.

The redistribution of teachers to cover all educational institutions in our sample on the basis of $2 \mathrm{~h} /$ week, allowed us to increase the coverage up $129.82 \%$ that is to say $18 \%$ or an average of 23 minutes per week for each class and student.

Table 2: Quantitative analysis of school time through the sample

\begin{tabular}{|c|l|c|c|c|c|c|}
\hline \multicolumn{2}{|c|}{ Nb hours per classes } & $1 \mathrm{~h}$ & $2 \mathrm{~h}$ & $3 \mathrm{~h}$ & $4 \mathrm{~h}$ and more & Total \\
\hline Scolarity Level & \multicolumn{5}{|l|}{} \\
\hline \multirow{3}{*}{ College school } & Nb. of Classes & 1 classe & 98 classes & 141 classes & 28 classes & 268 classes \\
\cline { 2 - 8 } & Hours & $1 \mathrm{~h}$ & $196 \mathrm{~h}$ & $423 \mathrm{~h}$ & $112 \mathrm{~h}$ & $732 \mathrm{~h}$ \\
\cline { 2 - 8 } & $\%$ & 0,37 & 36,56 & 52,61 & 10,44 & 100 \\
\hline \multirow{3}{*}{ Secondary school } & Nb. of Classes & 7 classes & 385 classes & 126 classes & $/$ & 518 classes \\
\cline { 2 - 7 } & Hours & $7 \mathrm{~h}$ & $770 \mathrm{~h}$ & $378 \mathrm{~h}$ & $/$ & $1155 \mathrm{~h}$ \\
\cline { 2 - 8 } & $\%$ & 1,35 & 74,32 & 24,32 & 0 & 100 \\
\hline
\end{tabular}




\section{2- Qualitative analysis of school time through the sample}

The purpose of this analysis is to focus on the time slots allocated to the teaching of EPS and distinguish slots most used (peak) against those used by the month compared to the general organization of the educational 'school (OP) along the day and throughout the week.

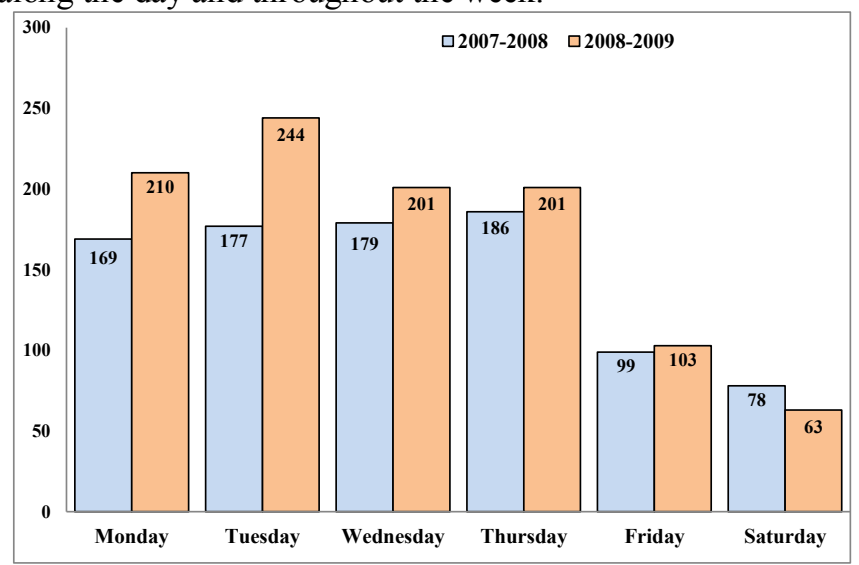

Fig 1: The time distribution of the activity of the EPS during the week morning and afternoon

Through the statistical analysis, we found a low use of the morning session in the teaching of EPS at the beginning and end of the week (Monday and Saturday) with a rate of (17\%) compared to the average. Much more, we chow a high use of the middle days of the week (especially on Tuesday and Thursday) for the activity of the EPS with a rate of (17\%) compared to the average. Also, the morning session is a meeting point for the teaching of EPS. $62 \%$ of EPS sessions take place during the morning sessions. And this contradicts the government's notes of Education which states that three quarters of the meetings of raw materials and materials of the industry (specialty) to be conducted during the morning sessions.

\section{3- The time distribution of activity along the EPS hours of the day:}

Our statistical data chowed that the first and last two hours of the morning and afternoon sessions are the lowest slots of the day or the number of hours in EPS drops to (- 8\%) compared to the average. Also, the peak hours during the day are located in the middle of the morning sessions (9am to 11am) and afternoon (15h to $17 \mathrm{~h}$ ) with a utilization rate and operating (8\%) compared the average, which represents a recovery recorded during the start and end of sessions deficit. Furthermore, it is noted that the above results are valid for two consecutive school seasons, which gives evidence that they are not random but are a reproductive phenomenon linked to one or more reasons not yet identified.

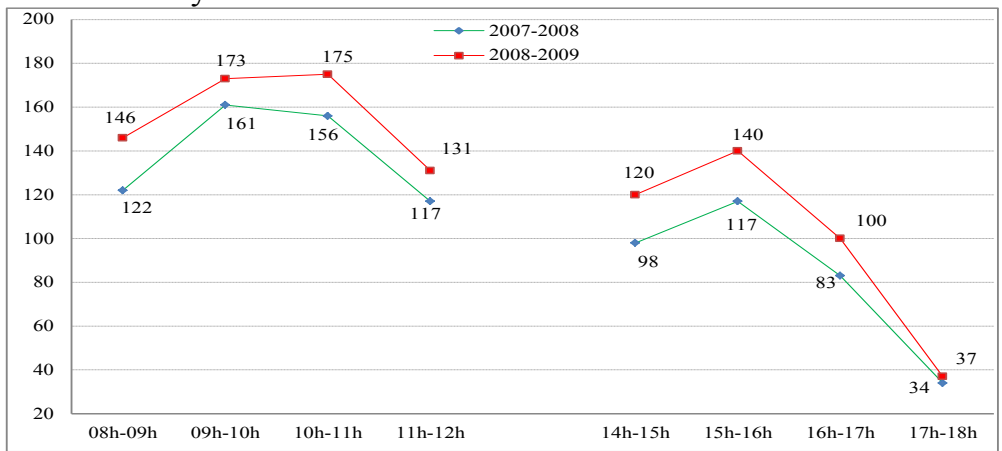

Fig 2: The time distribution of activity along the EPS hours of the day

\section{Discussion}

There is a discrepancy between the promulgated by the Ministry of Youth and Sports texts and those announced by the Ministry of Education on the time allocated to school discipline (especially in primary and secondary). This discrepancy highlights the problem of dual supervision exerted on matter by the two departments and the observed negative impact on the functioning of the material including the number of hours: In practice, the Ministry of Education and through internal departmental notes (9) forced school leaders to pursue an educational organization drawing of school reality and environment requirements for basic materials and violating the guidelines of the Ministry of youth and Sports.

Despite the human potential available in schools at the PE teachers, the number of hours allocated to pupils in preparatory and secondary education remains small and does not reach the required number in the 
existing legislation (especially in preparatory schools). The quantitative weakness of school time is accompanied by a gross disparity between the beneficiaries of the material relating to the principles of democratization of education, social equality and a sense of citizenship. This is not customary for all other school subjects, but is a feature of the EPS discipline.

The deficit hourly rate allocated to the teaching of the EPS is compounded by the situation sometimes alarming school sports infrastructure, lack of teaching materials and the loss of engine time commitment related to movement, change of clothes and poor educational organization. For "For the teacher, it is not possible to increase the program time in its class, it is only doing its job properly, it reduces the risk that politicians consider reduced hours EPS.(18)

The Qualitative analysis of school time, has allowed us to identify slots at high operating teaching EPS (peak): the morning sessions (62\%), the days of the middle of the week $(17 \%)$ and hours in the middle of the morning session and after - midi (8\%). These slots perfectly coincide with the phases of high intellectual vigilance of the student, as described in the various European studies on lap psychology and chronobiology. Paradoxically, after the morning sessions (38\%), the days start and end of week (17\%) and the start and end of the session $(8 \%)$ are the time slots less exploited for teaching EPS.

These statistical data coincide again with the phases of deterioration in alertness and intellectual abilities and motor sport and as described in the work on chronobiology discussed later performance.

\section{Conclusion}

The school time allotted to sport and physical education reflects the place that the matter took in the school system. Their quantitative and qualitative importances have a direct impact on the intellectual, moral and physical training of the child, and mark the learner's footprint. The Quantitative analysis of school time of the matter of sport and physical education has enabled us to see that the time provided for in the legislation (confusing and sometimes contradictory) are not met in daily practice, and the gap between the beneficiaries of the matter is too wide leading to a gross disparity. Paradoxically, the qualitative analysis of school time has allowed us to observe that the most favorable time slots for teaching during the day and during the week, those that correspond to a state of mental and physical alertness, are reserved in priority to teach sport and physical education. In fact, the matter of sport and physical education is not in an equality position with other school matters but it rivals the basic ones.

\section{References}

[1]. Journal Officiel de la République Tunisienne. (2013). Décret n² 2013-77 .24 janvier 2013.

[2]. Pothier P. Y. (2012). A propos des rythmes scolaires et l'aménagement du temps scolaire .SNEP académique.

[3]. Ministère de l'Education Nationale Tunisienne. (2011).Propositions pour la réforme du système éducatif .Espace manager.com .02 Décembre 2011.

[4]. Journal Officiel de la République Tunisienne. (2008).Loi n²008-9 du 11 février 2008 modifiant et complétant la loi d'orientation ${ }^{\circ}$ 2002-80 du 23 juillet 2002, relative à l'éducation et à l'enseignement scolaire.

[5]. Nations unies. (2003). Le sport en tant que moyen de promouvoir l'éducation, la santé, le développement et la paix. Résolution adoptée par l'Assemblée générale. Cinquante - huitième sessions. Point b 23, de l'ordre du jour. 3 nov 2003.

[6]. Charmeux E. (1975). La lecture à l'école. Ed. CEDIC. Nathan. p 32.

[7]. Chraiet. A.Rythme scolaire et rendement éducatif- Forces et faiblesses du système.la presse.tn.20 septembre 2012.

[8]. Missaoui O.E. Quels rythmes scolaires adopter ? Thot cursus .formation et culture numérique. 19 septembre 2012.

[9]. Ministère de l'Education Nationale Tunisienne. Guide des normes pédagogiques et organisationnelles de confection des emplois du temps. Note $\mathrm{N}^{\circ} 17312$ du 29/08/2009.

[10]. Chraiet A. (2012). Rythme scolaire et rendement éducatif- Forces et faiblesses du système. La Presse.tn.20 septembre 2012.

[11]. Theunynck D. (2007). chronobiologie et APPS activités physiques, performances et santé.Laboratoire de recherche littorale en activité corporelles et sportives .EA 4110.

[12]. Montagner H., Testu F. (1996).Rythmicités biologiques, comportementales et intellectuelles de l'élève au cours de la journée scolaire. Pathol Biol 1996, 44 : 1-15Montagner H., Les rythmes de l'enfant et de l'adolescent, ces jeunes en mal de temps et de l'espace. Stock Laurence Pernoud, Paris, 1983.

[13]. Testu F.(1994). Quelques constantes dans les fluctuations journalières et hebdomadaires de l'activité intellectuelle des élèves en Europe. Enfance.1994b, $4: 389-400$.

[14]. Xavier E., Theunynck D. (2005). Recherche littorale en activités corporelles et sportives - cote d'opale, Dunkerque-2005.

[15]. Reilly T. (1990). Human circadian rhythms and exercise. Crit Rev Biomed Eng, 1990, 18:165-80.

[16]. Sinnerton S., Reilly T. (1991). Effects of sleep loss and time of day in swimming. In Mac laren D.,Reilly T., Lees A., Hughs M. Biomechanics and medicine in swimming VI. London. F.N. Spon.

[17]. Piéron M. (1992). Pédagogie des activités physiques et du sport. Revue EPS.Paris. 1992. p102 